An Economic Analysis of Twitching Behaviour and Species Rarity

Mike Brock

School of Economics

UEA

Iain Fraser*

School of Economics

University of Kent

Cherry Law

Department of Public Health, Environments and Society

London School of Hygiene and Tropical Medicine

\author{
Simon Mitchell \\ School of Anthropology and Conservation \\ University of Kent \\ David L. Roberts \\ School of Anthropology and Conservation \\ University of Kent
}

May 2020

Address for correspondence:

Iain Fraser

School of Economics

Kennedy Building

Park Wood Road

University of Kent

Canterbury

Kent, CT2 7FS

+4401227823513

i.m.fraser@kent.ac.uk

Acknowledgements

We acknowledge the final support provided by the Eastern ARC Seed Fund that enabled us to undertake our survey design and data collection. 


\title{
An Economic Analysis of Twitching Behaviour and Species Rarity
}

\begin{abstract}
Avid birdwatchers, or 'twitchers', expend a considerable amount of money and time pursuing viewing experiences of rare or vagrant species. By vagrant species we mean a species found outside its normal range/distribution. To enhance our understanding of this form of behaviour, we present results from a UK survey of twitchers. First, we examine the relationship between cost and rarity based on actual viewing experiences. Our statistical results reveal that the relationship between cost and rarity is positive and very inelastic. Second, we present results from a hypothetical Best-Worst Scaling exercise examining aspects of species rarity. We find that rarity is a more nuanced construct than simply the frequency with which a vagrant species has appeared. Our results provide insights into the meaning of rarity, as well as the economic value attach to it and why.
\end{abstract}

Key Words: Twitching; Rarity; Travel Cost Valuation; Best-Worst Scaling.

\section{Introduction}

There are many examples in society of groups or individuals whose behaviour is motivated by the need to see, acquire or experience a particular event or happening. What can set this type of behaviour apart from many others is the obsessive pursuit of these experiences. One such example that occurs in the United Kingdom (UK) is referred to as 'twitching' (chasing rarities in the United States (US)). Twitchers are birdwatchers who travel to see rare bird species, especially vagrant non-indigenous bird species, even in the most remote parts of the UK. For example, in April 2017 several groups of people chartered four planes to fly to Orkney because an American species, the Red-winged Blackbird (Agelaius phoeniceus), had been spotted in the UK for the first time. As such, twitchers are revealing strong preferences to see a rare bird, at least in terms of its presence in the UK and the importance they attach to seeing and experiencing such a bird. Furthermore, the likelihood of a future sighting is unknown and this only increases the value twitchers place on experiencing a vagrant bird species. Fundamentally, it is the experience of seeing the bird in a specific context that matters - the Red-winged Blackbird is one of the most populous bird species in North America and so in no way is it rare in the same way as species that are listed on the IUCN Red List. Thus, it is only through its 'out-of-location' appearance that value is derived.

In this paper, we present findings from a survey of UK twitchers with the objective of furthering our understanding of this pursuit. This work seeks to examine the extent to which 
twitchers value rarity when it comes to wanting to see particular vagrant species. To undertake this analysis, we define "rare" as birds that are not typically found in the UK as defined by the British Birds Rarities Committee (BBRC) ${ }^{1}$.

"BBRC assess all records of rare taxa that are on Cat $A$ of the British List. Cat $A$ is for those species/taxa that have occurred in the wild since 1950. We also assess sightings involving a potential new taxon (species or sub-species). If the ID is accepted then the record is forwarded to the BOURC. BOURC then look at the record again, both to identification \& particularly for provenance of that First record - provenance means that the sighting is of a naturally occurring bird.”

This definition of rarity is particularly useful for the research we present, because it provides an objective numerical count of the number of times rare species have been observed in the UK. As our research will reveal, although this definition provides important insights into explaining twitching behaviour and value attached to rarity it is also subject to limitations that we identify and discuss within our analysis.

In terms of understanding the value attached to observing rare birds, there are several reasons. First, many twitchers are motivated by their "life-list". Life-lists frequently have a geographical reference such that there is a known set of species to be seen e.g., regional, national or even global. However, a life-list can be expanded by viewing vagrant birds. Efforts to expand a life-list can be viewed as a form of collecting. ${ }^{2}$ What motivates collecting behaviour is relatively under-researched within economic valuation literature. Most literature focuses on the physical collection of artefacts (e.g., Belk, 1995), which indirectly relates to the literature on positional goods (Solnicka and Hemenway, 1998).

Second, the value attached to seeing a rarity is that there is simply a worth associated with seeing something rare. The value associated with rarity has typically been examined with regard to owning or possessing rare objects (e.g., Koford and Tschoegl 1998 and rare coins). In the case of birds, rarity value has been examined in the context of the caged-bird market

\footnotetext{
${ }^{1}$ https://www.bbrc.org.uk/

${ }^{2}$ Examples in the literature include Mardon and Belk (2018) who consider digital collecting whereas Apostolou (2011) looks at fossilised dinosaur eggs. There is also literature on the experience economy and collecting experiences (Pine and Gilmore, 1998). Individuals' also obtain relatively higher satisfaction from experiential versus material consumption (Gilovich, Kumar and Jampol, 2015).
} 
(Krishna et al., 2019). ${ }^{3}$ In the case of vagrant birds, rarity takes a different meaning as the value attached to experiencing a rarity increases with the fewer individuals who manage to experience it. ${ }^{4}$ This value can also increase if twitchers perceive that the likelihood of seeing the species in the foreseeable future is low. Also, species which are known to have previously visited, but before most active 'twitchers' could see it, are highly valued. Records of the most extreme rarities can develop a whole folklore and mystique around them.

Third, one could gain contentment from being part of a bird-watching community, conducive with welfare enhancing inter-connectedness (Diener and Biswas-Diener, 2008). Twitching may also deliver utility through the unpredictability of the activity itself. Whilst appreciating that humans' display risk aversion in many domains of life, it is also true that we derive utility from there being (a degree of) uncertainty in leisure activities. Thus, a twitcher may derive excitement by not knowing when and where the next vagrant sighting will be or, should they travel once a bird has been spotted, whether or not they will see the bird.

In this paper, we examine two facets of twitcher behaviour to enhance our understanding of how they value rarity. First, we consider the relationship between the cost of twitching and how this correlates with species rarity. Second, we examine how preferences for particular species are explained by rarity. To undertake this research, we implemented an online survey of twitchers in 2018. Our survey collected both revealed preference data on actual twitcher activity plus stated preference data from a Best-Worst Scaling (BWS) exercise.

The revealed preference data we employ in this study is somewhat unique, reflecting the actual behaviour of twitchers. Twitchers will travel to many different sites as and when a vagrant bird arrives "out of the blue". This means there is no count measure of frequency of travel to the specific site. For each respondent, we simply have information about a one off trip to a given site. We also do not have data for visits to only one site made by all of the respondents. Thus, the data we have does not conform to a standard travel costs model (TCM) data type and this is why we do not perform standard TCM analysis (Haab and McConnell, 2002). What we have is the cost incurred in experiencing vagrant species and

\footnotetext{
${ }^{3}$ Krishna et al. (2019) note that species that are rare in the wild may no longer be valued as highly because the scale of the caged trade has reduced rarity for consumers.

${ }^{4}$ Callaghan et al. (2018) reference the film "The Big Year" (https://en.wikipedia.org/wiki/The Big Year) a comedy about the extremes twitchers go to see rare species. Sheard (1999) compares the pursuit of rare birds to that of a competition.
} 
how it varies by rarity. Thus, with this data, we estimate a cost elasticity for species rarity using two data sets and several model specifications. In addition, our BWS survey yields important insights into meaning of species rarity. It was our prior that the strongest preferences will be expressed for the most-rare species. However, the BWS reveals that our survey respondents have a more nuanced view of rarity that warrants further examination. Taken together our results reveal how species rarity does influence twitcher behaviour, but that rarity is a complex construct.

\section{Antecedent Literature}

As shall be discussed here, the type of value which rare vagrant birds evoke is quire unique within the field of environmental economics, and this in itself partially explains the hybrid valuation technique that we employ within this study. Although potentially tempting to think of twitching as an activity motivated by conservation, this is not necessarily the case. As such, the classic forms of non-market valuation typically applied to birds in terms of conservation do not apply here (Veríssimo et al., 2009; Bristol et al., 2014; Steven et al., 2017; Krishna et al., 2019). This is because vagrant species, whose likelihood of future sighting is unknown to the respondent, is not one that the twitcher is seeking to 'protect'. Indeed, they instead attribute worth to the fact that a species is not being seen in situ - it is because the bird is out of context and will most likely only remain in the vicinity fleetingly that a value is generated.

If one were trying to define this study as employing a revealed preference (RP) or stated preference (SP) technique, we believe it would broadly fall into the former group. This is because the primary aim of this study is to uncover the real decisions which twitchers have made and are asked to recount the distances travelled to visit sites where rare and vagrant birds have been sighted. Whilst one might argue the mechanism for achieving this relies upon truthful responses to survey questions, this is not distinct from many standard mechanisms used within a TCM elicitation process. The major difference is that whilst previous TCM studies use this information to establish values for one specific site, we instead focus on how travel costs can be used to compare and contrast differences in the species-level value twitchers hold. Nevertheless, because our study does want to also understand the different choices twitchers would make under hypothetical future scenarios, we do include a stated preference component within our work, namely the BWS exercise. It is out belief that 
combining these two exercises is the best way to meet our aims of establishing a value placed on rarity and gaining insights into this quite unique type of wildlife valuation.

In terms of the valuation literature our study contributes to a small number of papers using revealed preference data to examine the economics of twitching behaviour. For example, Booth et al. (2011), examined how the number of twitchers in the UK attending vagrant sightings varied by the degree of species rarity i.e., the Brown Flycatcher and the RedFlanked Bluetail. They defined rarity to be the "average number of sightings of the species in the UK per year since recoding for the species began..." (p. 2729). With this measure of rarity they estimated the elasticity of visitor numbers to rarity to be -0.217 indicating a highly inelastic relationship between the number of twitchers visiting a site and the rarity of the species in question. However, this elasticity does not provide an economic understanding of the costs that twitchers are prepared to expend in order to see rare species. There are also a number of related TCM studies. For example, Callaghan et al. (2018) undertook a TCM study for a specific vagrant bird in the US, the Black-backed Oriole which is endemic in Mexico. Using a zonal TCM, they estimated the total economic value associated with the twitching event at approximately \$220,000 US. Similarly, Callaghan et al. (2019) undertook a TCM study in Australia for birdwatchers attempting to see the vagrant Aleutian Terns. They reported economic values of approximately $\$ 150,000-\$ 235,000$ US. Both of these studies discuss the economic consequences for avitourism based on twitcher activity and the reported monetary estimates. Finally, Kolstoe and Cameron (2017) present a TCM study reporting that the variety of bird species at a particular viewing location is negatively related to the marginal utility obtained. This result occurs because the bird watchers are deriving less utility from an additional species that they see at a bird watching site they have previously visited. However, they also find that endangered species yield positive utility, and this result has also been noted for other species such as fish (e.g., Meyerhoff et al., 2019). This could relate to gaining utility for seeing rare species, especially vagrants that may or may not appear in a given geographical location again.

In terms of the stated preference literature there are no existing studies that examine twitcher behaviour. However, there are an increasing number of discrete choice experiments (DCEs) examining avian topics (e.g., Brock et al., 2017; Czajkowski et al., 2019). However, DCEs are relatively demanding survey instruments for respondents to meaningfully engage with. In contrast, BWS exercises, an alternative type of stated preference method, are easier to 
implement as they only require respondents to indicate best and worst options from a set of available possibilities - a much simpler task. By requiring respondents to indicate best and worst options, this technique assumes the principle of ordinality in the survey data being collected. Thus, preference elicitation simply focusses on the ordering of choices over two or more options without the need to define the strength of those preferences (Louviere et al., 2015). As explained in detail by Louviere et al. (2015) BWS has a long lineage in marketing and more recently economics (e.g., Scarpa et al., 2011; Petrolia et al., 2018; De Brauwer and Burton, 2018). The popularity of the method has grown because it has good discriminatory power compared to other statistical approaches when comparing alternative options in a choice context.

Surprisingly, the application of BWS within the conservation literature is very limited (e.g., Scarpa et al., 2011) when compared to the number of DCE studies. A recent example of BWS is provided by De Brauwer and Burton (2018), who examine scuba diver species preferences for muck diving in Southeast Asia. This application neatly illustrates how a BWS exercise can be used to reveal preferences in a manner that is far less demanding for survey respondents than a DCE.

\section{Survey Data}

In 2018, we distributed an online survey instrument examining birding activities with a specific focus on rare (vagrant) birds seen in the UK. ${ }^{5}$ The survey instrument was advertised to the twitcher community via press releases on both the Rare Bird Alert website and Birdguides. ${ }^{6}$ The survey was designed to examine twitcher motivations and levels of personal investment they make in the activity. The survey was composed of several sections, including questions about the self-reported best twitching trip in 2017 plus the BWS exercise. In total, we collected 224 survey responses for the TCM. With regard to the BWS exercise, we collected 125 responses.

In terms of twitching frequency, respondents travelled to view rare or vagrant birds in 2015, 2016 and 2017 on average 14, 15 and 14 times respectively. The mean distance travelled was

\footnotetext{
${ }^{5}$ The survey instrument is provided in an appendix to this paper.

6 https://www.rarebirdalert.co.uk/v2/Content/index.aspx and https://www.birdguides.com/news/majoronline-survey-launched-to-assess-the-economics-of-rarity-in-bir/
} 
505 miles (with a median of 450 miles and mode of 500 miles). These distances are not surprising given that many of the likely arrival points for vagrants in the UK frequently requires extensive travel.

Turning to the best twitch in 2017, we asked what species had been seen or attempted to see (a list of species and locations is provided in the Appendix). In terms of mode of transport used to travel, car travel was by far the highest at 96 percent, followed by ferry at 13 percent. This reflects the fact that in order to reach some UK twitching destinations requires leaving the mainland. 42 percent of respondents travelled alone, and 44 percent travelled with only one other person. Importantly, 72 percent of respondents only undertook a day trip and 82 percent stated that the bird watching was the only activity they undertook on this specific trip.

In terms of the costs incurred for undertaking the best twitch in 2017, the sample average is $£ 114$ (with a median of $£ 40$ and a mode of $£ 0$ ). However, this comes with significant variation, including many missing values for many respondents as well as a maximum reported cost incurred of $£ 1,400$. As a result of the varying quality of reported cost data, as well as the many missing responses, as we explain below, we supplement this data with estimates of travel cost by car using a road distance travel planner. Although this means we are combining reported and estimated data many of the non-responses clearly required a level of expenditure to see a particular species.

In terms of socio-economic descriptive statistics, our sample is predominately male, with an average age of 49 years and an average level of income well above the UK national average of $£ 34,200$ in $2017 .^{7}$ As noted by Booth et al. (2011) a high percentage of twitchers are members of an associated conservation organisation. In our case, $79.9 \%$ of respondents are members of the RSPB. Also, the average level of education is relatively high. As we might expect, many of our respondents are connected to other twitchers by means of social media, although twitcher specific alert services are used typically by less than $50 \%$ of our respondents. These results suggest that many of our respondents interact with other twitchers directly, at least in relation to sharing information (See Appendix for details).

\footnotetext{
${ }^{7}$ https://www.ons.gov.uk/peoplepopulationandcommunity/personalandhouseholdfinances/incomeandwealth /bulletins/householddisposableincomeandinequality/yearending2018
} 


\subsection{TCM Data Sets}

With the data collected on actual bird watching trips, we constructed two data sets. The first (the "One-Trip data set") is the data we collected relating to their most important twitch in 2017. This data set is composed of 224 twitching trips covering self-reported estimates of travel costs as well as other associated costs such as accommodation and food. The data collected from this set of questions allows us to develop a trip specific measure of cost. The second data set we developed is referred to as the "Multi-Trip data set". This data set was constructed from answers to the following question for 2017: "List no more than 5 of the most recent locations you have visited and the birds observed or you attempted to see." This question allowed us to construct a data set composed of 1,042 twitching activities (demonstrating that many respondents did offer five trip descriptions).

At this point it is worth reiterating that the data we have collected and used to construct both data sets is not like existing travel cost data. For the One-Trip data set the 224 observations are one data point per respondent. The respondents have visited a large number of different sites. Thus, there is no measure of frequency of visit to a specific site. There is also no one site visited which makes this data different to that used by Callaghan et al. $(2018,2019)$ who present results for a standard TCM. For the Multi-Trip data set there are very few repeat visits in the data set as the 5 sites visited are generally different and each visit is simply determined by the appearance of a specific bird species.

As already noted, the cost data we have collected from our survey participants is somewhat limited. As a result, we supplemented this data with estimated travel costs for all respondents in an effort to deal with this limitation. Specifically, as we know a respondent's home location up to the first three or four digits of their post code, this allowed us to estimate the cost of travel using a road distance route planner. ${ }^{8}$ In addition, when the specified location was on an island, we included an estimate of the ferry cost. For One-Trip data set, we combined the estimated travel cost data along with the self-reported estimates of costs incurred. In contrast, we did not include any other cost estimates in the Multi-Trip data set. ${ }^{9}$

\footnotetext{
${ }^{8}$ We employed Route Calculator: https://routecalculator.co.uk/

${ }^{9}$ We do not impute the value associated with the travel experience or opportunity cost of time. Kolstoe and Cameron (2017) note that value of travel time is typically imputed to be one-third of the average wage.
} 
We took this approach to assess if our results from both data sets would be consistent given the way we generated our measure of travel cost for the One-Trip data set.

For both data sets, we take all species reported by the respondents and generate a measure of rarity. For most species reported by participants, a measure of rarity exists in the BBRC records. The BBRC provide an annual and total cumulative count of all rare and vagrant taxa. We employed the total cumulative count as a measure of rarity. ${ }^{10}$ Thus, the rarest species have a count measure of one. For those birds identified by survey respondents as rare, but not included on the BBRC list, we examined data on annual sightings from the British Ornithologists' Union (BOU) and the RSPB and made subjective judgements about rarity. ${ }^{11}$ These subjective judgements amounted to estimating the likely number of times the species would be viewed annually. To assess the impact and potential bias these subjective measures of rarity could introduce into our analysis, we employ several model specifications for which we exclude species not in the BBRC list. Thus, we generated a rarity score for every species in our data set either by employing the BBRC cumulative count or the subjective measure described.

Finally, we took the inverse of the rarity count and its log. The former transformation was to improve interpretive ease (i.e., the intuition is simply that greater rarity - as defined -will likely be valued more) and the latter ensured that our model generated the cost estimate as an elasticity (i.e., elasticity of cost with respect to rarity).

\subsection{BWS Survey Design and Data Collection}

A key decision in designing a BWS survey instrument is the type of design to employ. We have employed the approach that is typically referred to as the profile case (Louviere et al., 2015). With this design, survey respondents are presented with profiles and they select their best and the worst options within each given profile. We developed our profiles (or groups) in terms of rare bird species that our respondents would most/least like to see. Specifically, we developed a list of 30 rare and vagrant birds that twitchers could or might expect to see in the UK in the future. These 30 birds were then placed in six groups (profiles), each containing five species.

\footnotetext{
${ }^{10}$ https://www.bbrc.org.uk/main-information/statistics

${ }^{11}$ https://www.bou.org.uk/british-list/
} 
The profiles were strategically designed to include birds of varying degrees of rarity. The BBRC definition of rarity was used to develop four of the six profiles.

We first constructed a group with very rare species ("Extremely Rare") and then constructed three further groups ("Rare 1", "Rare 2" and "Rare 3"), each composed of a varying mix of rare species. For the two remaining groups, we employed subjective judgements about bird species to capture other aspects of rarity. Specifically, in constructing the rarest species group ("Future"), we included species that have yet to arrive in the UK, but whose likelihood of arrival is positive. For example, we included the Azure Tit, a species which has never occurred in a wild state in the UK. Within the twitcher community, the following view has been expressed about degree of excitement that seeing this bird would generate in the UK:

"A wintering bird in a British location would no doubt break all records for the number of observers paying homage to its presence!" 12

Also within this group, we included the Slender-billed Curlew. The bird is so rare that in fact it is now possibly extinct with the last recorded sighting being in 1995. The remaining group ("Scarce") was composed of rare species, but not so rare that they typically attract the same degree of interest as those species listed by the BBRC. A summary of the species in each group and the assessment of rarity is provided in Table 1.

\section{\{Approximate Position of Table 1\}}

Having identified our groups of bird species, we then generated our profiles. To do so, we combined the groups using an Orthogonal Main Effects Plan (OMEP). In total, we generated 25 choice situations, which we blocked into five groups of five choices using the Orthoplan command in use SPSS ${ }^{13}$. For each BWS choice task, the respondent needed to identify the best and then worst bird species from the six provided. We framed the choice very simply as:

"All we wish to know is in this hypothetical situation is which bird do you think you would most/least enjoy seeing?"

An example of a BWS choice task is shown in Figure 1.

\section{\{Approximate Position of Figure 1\}}

\section{Statistical Models}

\footnotetext{
12 https://www.birdguides.com/articles/western-palearctic/rare-western-palearctic-birds-azure-tit/

${ }^{13}$ For details on the Orthoplan command in SPSS, see: http://www.spss.com.hk/software/statistics/conjoint/.
} 


\subsection{Travel Cost Specification}

In this paper, we assume that seeing and experiencing a vagrant species is a function of the costs incurred in travelling to a specific site to see that species. In this way, we can assume that travel costs are a proxy for the price incurred for seeing rare birds. In our analysis we took our measure of rarity to be the dependent variable. Thus, our specification can be considered as being equivalent to a trip generating function for a conventional TCM specification (Haab and McConnell, 2002).

In terms of our model specification, we employed several variations for both data sets so to assess the robustness of key model estimates. For the One-Trip data set, we estimate a basic OLS specification. Next we estimate the "Rarity Index" model specification for which we remove data points for the least rare species i.e., not included in BBRC list. As noted, we include this specification so as to examine any potential bias from combining the BBRC score of rarity and our subjective measure. We also estimate a specification for respondents' who only made the trip in question to see a specific bird and they undertook no other activities (such as sightseeing), thus controlling for multi destination/purposes issues that can impact upon travel cost studies (Kolstoe and Cameron, 2017). For the Multi-Trip data set, we also estimate an OLS specification. The other model specifications include the Rarity Index specification and an unbalanced panel specification, employing a random effects model.

The set of variables we employ in our analysis is summarised in Table 2.

\section{\{Approximate Position of Table 2\}}

Our set of variables capture aspects of twitcher behaviour, including how the sighting of a rare bird is communicated, various environmental and conservation group memberships and a set of socio-economic and demographic attributes. Also, we attempted to keep both model specifications as similar as possible such that the only difference in the model specifications between data sets is that we include two additional variables in the Multi-Trip analysis: international travel (BEYUK); and total trips from 2015-2017 (TT).

A formal representation of the econometric specification we employ is presented in equation (1):

$$
\operatorname{lnRarity}_{i t}=\beta_{0}+\beta_{1} \operatorname{lnCost}_{i t}+\sum_{k=2}^{K} \beta_{k} X_{i t}+\varepsilon_{i t}
$$


where $i=1, \ldots, N$ are the respondents $(\mathrm{N}=224)$ and $t=1,2,3,4,5$ are the maximum number of trips reported for each respondent in the Multi-trip data set. For the One-Trip data set $t=1$ for all models. Next, $\beta_{0}$ is the intercept, $\ln$ Cost is the natural logarithm of the costs incurred in making a trip and $X_{i t}$ is a vector of explanatory variables specified in Table 2 . The final term in equation (1) is the error term that is of standard form.

Finally, an interesting feature of the analysis we present relates to the form of rarity we examine. As observed by Koford and Tschoegl (1998) when it comes to rarity, for many goods and services the assumption that demand and supply are independent may not hold. Indeed, in many cases suppliers of a good or service will 'produce rarity', as it is this quality that is demanded by consumers. However, in this case rarity will not be independent of quantity. For the choice behaviour examined in this paper (unlike goods and services that are produced) 'rarity' is not subject to supply-demand interdependency because the supply of rare species is generally exogenous. Certainly, the arrival of a particular species, as well as its location, is a truly stochastic event. However, it is worth noting that keen twitchers will holiday and travel to know "vagrant traps" especially those that are more remote and expensive to visit on an ad hoc basis.

\subsection{BWS Analysis}

We first calculate the BWS score following Casini et al. (2009). In this case the BWS score for an alternative $i$ is simply calculated as the difference between the sum of best and worst rankings as shown in equation (2):

$B W S=\sum B_{i}-\sum W_{i}$

Second, within each profile, a respondent selects the items (here species) that are considered the furthest apart, such that they maximise the utility difference. In this case, the BWS data can be modelled based upon Random Utility Theory (RUT) within a stochastic framework. In its most general form the basic RUT model can be expressed as follows:

$U_{i j t}=\beta_{i} X_{i j t}+\varepsilon_{i j t}$ 
where an individual $i$ obtains utility from an alternative $j$ from a choice set $t . \beta_{i}$ are the elements of a vector of utility parameters and $X_{i j t}$ is a vector of attributes. Here the vector of attributes are the species groups within the BWS profile design. $\varepsilon_{i j t}$ is the stochastic component. Next, we assume that individual $i$ selects the best $(j)$ and the worst $(k)$ pair of attributes from a profile. Here, the probability that respondent $i$ selects $j$ and $k$ is the largest difference in utility available within the set (i.e., $U_{i j t}-U_{i k t}$ ). If it is assumed that the stochastic component is independent and identically distributed, then the probability of selecting attribute $j$ as best and $k$ as worst can be expressed in a standard conditional logit (CL) format as shown in equation (4):

$$
P_{i j}=\frac{\exp \left(\beta_{j}-\beta_{k}\right)}{\sum_{j, k} \exp \left(\beta_{j} \text { Best }_{j}-\beta_{k} \text { Worst }_{k}\right)}
$$

Following Flynn et al. (2007), the CL models we estimate only require us to fix one level for one attribute to zero. The choice of which attribute to fix does not impact the model estimation, nor its results.

\section{Model Results}

\subsection{TCM ${ }^{14}$}

Our TCM results for the OLS and Rarity Index models for both data sets are presented in Table 3.

\section{\{Approximate Position of Table 3\}}

For the One-Trip data set the range of elasticity estimates for the cost parameter is between 0.42 and 0.51 revealing a positive relationship between a species' degree of rarity and the travel costs that twitchers are prepared to expend in order to see that species. Because this cost parameter is inelastic, this also implies that twitchers will spend (proportionately) more to see and experience rarer species. This result coincides with those reported by Booth et al. (2011), who demonstrated that more twitchers will travel to see a rarer species.

\footnotetext{
${ }^{14}$ For both TCM specifications, we considered the Ramsey RESET test as well as heteroscedasticity. Our model specifications pass the RESET test. When correcting for heteroscedasticity, the results remained unchanged. The additional model specifications estimated as robustness checks are provided in the Appendix.
} 
Turning to the other explanatory variables, we see that use of social media (i.e., Facebook) is negatively related to rarity but the use of texts is positively related. We also see that the Rare Bird Alert pager service and the Birdguides web subscription are both positively related to rarity. Next we see that being a member of the BOU is the only positive and statistically significant variable. The fact that the BOU is positive and statistically significant, but being a member of the RSPB is not, indicates that membership of a more popular organisation does not inherently indicate a strong preference for seeing rare or vagrant species. Indeed, the BOU maintains the British list of bird species and is more engaged with analyses of ornithological science, whereas the RSPB is a more general conservation organisation and is largely unconnected to the pursuit of rare birds.

Turning to the Multi-Trip results, we can see that for the OLS specification the results are similar to those of the One-Trip specification. The only exception here is when we examine the Rarity Index model specification such that the cost elasticity estimate falls to 0.29 . The implication here is that the travel cost elasticity with respect to rarity becomes more inelastic as we consider the rarer species. This difference is almost certainly a function of the greater variation in bird species in the Multi-Trip data set and the within-sample costs incurred, which are proxied by the estimated travel costs.

The Multi-Trip specification included two additional explanatory variables compared to the One-Trip data set. First, we find that for those twitchers who are prepared to travel beyond the UK (BEYUK), there is a negative relationship with rarity, implying that being prepared to travel overseas is not a positive predictor of wanting to watch rare vagrant birds in the UK. This result may well be picking up a confounding effect - those twitchers who travel overseas for bird watching may be enjoying additional complementary benefits from the trips over and above seeing rare species. It is also the case that what is considered rare in an overseas context is not the same as that which we have defined in terms of vagrant birds in the UK. Second, the variable measuring total twitching trips made over the last three years (TT) is also negatively related to rarity of birds watched. This implies that it is not necessarily the quantity of twitching activity that predicts the willingness to travel to see the rarest birds. This result supports the idea that, when it comes to the rarest species, it is the need to experience these that motivates travel far more than seeing a "reasonably" rare species. It is also true that twitchers who have seen more species will then naturally have fewer species 
that they can add to their life-lists in a given year. For a twitcher who has already seen 200 species, there may be the opportunity to add 20 new species in a given year, whilst a twitcher who has seen over 500 species is closer to the asymptote of the entire British list. On average, they probably only have an opportunity to add five new species to their list in a given year.

Turning to the remaining explanatory variables, many of the information services provided are statistically significant and positively related to rarity. As with the One-Trip data set, the exception to this is the use of Facebook. When we consider membership of bird and wildlife societies, we find that membership of the BOU is negatively related to rarity which is in contrast to the One-Trip results. In addition, being a member of the National Trust (NT) is negatively related with the implication being that undertaking twitching is not necessarily positively correlated with wider attitudes to conservation. We also find mixed evidence regarding the relationship between rarity and various socio-economic measures. In general, education (negatively-related) and income (positively-related) are most frequently statistically significant across specifications. We might have expected both measures to be positively related, but given the relatively older average age of the sample (as well as the gender composition)

\subsection{Best-Worst Scaling Score Results}

We first estimated the BWS scores by species and then by species group using the BWS score formula. The formula simply sums all of the times a species within a specific group (i.e., Rare 1) was ranked as the best and as the worst, with BWS score calculated as the difference between the sum of best and worst. So for "Rare 1", we derived a best sum of 66 and a worst sum of 47 yielding a difference of 19 as the BWS score. As one might expect, the highest and lowest BWS scores are for the "Future" group $(=250)$ and the "Scarce" group (=409) respectively. The "Future" group (i.e., Azure Tit, Black-throated Blue Warbler, Bonelli's Eagle, Intermediate Egret, Slender-billed Curlew) was composed of species that have not yet been recorded in the UK, but may potentially arrive at some point and so are, by definition, very (very) rare. In contrast, the "Scarce" group (i.e., Common Rosefinch, Dotterel, Grey Phalarope, Red-backed Shrike, Velvet Scoter) although composed of a relatively uncommon group of birds, are, by the standards of twitchers, not so difficult to encounter as to motivate 
them to visit these sites. As such, the "Scarce" group generated only three 'best' choices across all survey respondents.

Another interesting result that emerges from this analysis is that for the "Rare 3" group, we find a relatively high BWS score $(=110)$ compared to the Extremely Rare group $(=24)$, the Rare 1 group (=19) and Rare 2 group (=6). Looking at the species level data, we can see that this result is driven by the high positive BWS scores for two species in particular; Blackbrowed Albatross and Gyr Falcon. This implies, quite logically, that other features besides rarity raise the relative attractiveness of bird species to twitchers and raises an interesting question as to the relative importance of rarity as defined here. We return to this issue below.

Next, we estimated the CL econometric specification. As noted, we only have to fix one of the attribute levels (here a particular species) when estimating this model. In our analysis, we 'fixed' the last species in terms of alphabetical order and thus interpret our results indexed relative to the Western Sandpiper. Within our design, this bird is a relatively rare vagrant, with only nine sightings to date. Nevertheless, these results are statistically robust to the choice of which species was fixed. The results of the CL estimation are presented in Table 4.

\section{\{Approximate Position of Table 4\}}

The CL estimates are relative to the omitted species with a positive estimate attracting positive utility and negative the opposite. Given the design of our BWS, we would assume, a priori, that the species we placed in the "Future" group would attract the strongest positive preferences because they are the least likely to be seen and hence should be valued very highly by the twitcher community. All of the "Future" group species (except Intermediate Egret) are strongly preferred. The lack of finding for the Intermediate Egret might reflect the fact that respondents subjectively dismiss the potential likelihood of the species ever arriving in the UK. However, this seems unlikely given that the Slender-billed Curlew is likely extinct, and should therefore be considered by most twitchers as extremely unlikely to ever be seen in the UK. Indeed, it is more likely that weak strength of preference expressed for Intermediate Egret is because it has low morphological disparity compared with other Egret species already found in the UK (i.e. Great White Egret (Ardea alba) and Little Egret (Egretta garzetta)). Similarly, the Intermediate Egret might be considered "boring" given that they are so abundant in other parts of the world. 
The second most-rare group are the "Extremely Rare" group (i.e., Double-crested Cormorant, Eastern Bonelli's Warbler, Rufous Bush Chat, Ruppell's Warbler, Sociable Plover). In this case two out of five have a negative estimate and three positive estimates that are all quite large. Thus, there is not a uniform positive preference to see species of this group. In contrast, when we consider the "Scarce" group these all have negative value reflecting the fact that, although rare, they are seen with sufficient regularity in the UK to no longer attract the same degree of interest.

In addition to estimating the basic CL model, we estimated a number of specifications in which we interacted various socio-economic characteristics with the set of attributes. In virtually all cases, we found that the interaction specification yielded marginally small improvements in model log likelihood scores, but insufficient to be statistically significant given the additional number of model parameters. Our strongest result related to the maximum distance a respondent was prepared to travel to see a rare vagrant species. The overall lack of statistical significance resulting from the inclusion of socio-economic data in our econometric specification is possibly due to the fact that the likely explanatory variables which define choice will be latent constructs and not observable characteristics.

Next, we compare the results generated from the BWS score and the CL in order to assess how these results correlate with our measure of species rarity. To do this, we first estimate the correlation of the rank order of species generated by both methods. We find that there is a strong correspondence between the rank order of species identified by the BWS scoring method and the CL estimates with the correlation between the ranks generated being 0.993 . Thus, both methods give very closely related results and this is in keeping with the findings reported by De Brauwer and Burton (2018).

We also compared our rank order results with our initial measures of rarity derived from the BBRC lists plus our own subjective judgements about bird species rarity. The data are presented in Table 4. For two groups, "Future" and "Scarce", we do not have BBRC scores. Here, we gave a score of zero for the "Future" species as, by definition, they are yet to arrive. In this case, we find that the correlation with the rank order of species from BWS score and the CL is 0.47 . If we drop the "Future" group scores of zero, the correlation only changes marginally to 0.48 . The much lower correlation between choices made and the BBRC measure of rarity can potentially be explained by other features of the bird species that were 
included in our BWS design. For example, we included the Double-crested Cormorant in our list as an example of an extremely rare vagrant (it has only ever been seen on one occasion in 1989). Despite this degree of rarity, it was ranked lowly by our survey respondents at 25 out of 30. This lack of interest from respondents could be that they discount its likely arrival in the UK very highly, or potentially arises through its strong similarity to other species already present in the UK. This latter point echoes that made for the Intermediate Egret earlier. Another species for which there is difference between the rank scores and the BBRC score is the Sociable Plover (also known as the Sociable Lapwing). It ranks third highest, despite having a BBRC score placing it much lower in terms of BBRC rarity. However, this species has not been seen since 2008 and, as such, it is likely that the aggregate BBRC score does not fully capture rarity with regards to 'time since the previous viewing experience'. If this is the case, this could suggest that the disinclination to select the Double-crested Cormorant could relate to its similarity to other commonly occurring species (i.e., Great Cormorant (Phalacrocorax carbo)). Another aspect that potentially determines twitchers' preferences is potentially revealed by the Gyr Falcon. Although having a relatively high BBRC score, so not that relatively rare, it was a highly ranked choice amongst respondents. What might be driving this result is the fact it is a charismatic bird of prey - the largest of the falcon species. The findings of the correlation statistics thus indicate that twitcher behaviour, although in part is determined by rarity as measured by the BBRC, may also be driven by other aspects on a species-by-species basis.

\section{Discussion and Conclusions}

In this paper, we present results from a survey implemented with twitchers in the UK in order to gain a greater insight into the value they attach to rarity. Our survey was composed of two data collection activities that allowed us to examine both revealed and stated preferences. Our first piece of analysis examined the relationship between cost and rarity based on actual viewing experiences. Our results show, perhaps unsurprisingly, that the relationship between cost and rarity is positive and inelastic. This implies that sightings of extremely rare vagrant birds will result in twitchers spending relative high sums of money to see the species in question. In many ways, our results confirm the anecdotal evidence that is frequently reported in the media about groups of twitchers descending on a location very rapidly once a particularly rare and/or vagrant species has been identified. This finding has also been reported by Callaghan et al. $(2018,2019)$ for TCM studies in Australia and the USA. In 
addition, our rarity elasticity result provides empirical support, albeit in a system where consumption is non-destructive rather than destructive, for the anthropogenic Allee effect (Holden and McDonald-Madden, 2017).

Turning to our BWS survey, we find that those birds profiled as most rare generally attract the strongest positive preferences, whereas those seen more frequently attract much less interest. These results reveal an inherent and shared knowledge of species rarity amongst our group of survey participants. However, there are some notable differences between which species are preferred to be seen compared to the measure of rarity we have employed. We conjecture that these differences may revolve around taxonomic information and preferences. For example, people may prefer to see birds of prey or birds that are visually distinct from resident species. Therefore, one very important question that emerges from our research relates to how we define 'rarity' and how we might use this to better understand the strength of twitcher preferences. Although species rarity as we define it (i.e. based upon the frequency of sightings on the BBRC list) is an objective measure, this might be too narrow. One adjustment could look at the dynamic frequency of sightings as opposed to the total number of times a species has been seen. It is unlikely that many twitchers have been active for more than 30 years and over this time period species abundance and the knowledge of how to identify certain vagrants has changed considerably. This has, in turn, impacted on and produced big shifts in how regularly recorded and therefore 'desirable' some species are. As an example, the Pallid Harrier or Citrine Wagtail are now 'expected birds' along the UK east coast in an average year, whilst global population declines in the Yellow-breasted Bunting mean it has become so rare it is recorded in the UK only once every 5-10 years.

Another (yet associated) way in which we could adjust our measure of rarity would be to consider when the last 'twitchable' record took place. This adjustment would take account of when there was last an opportunity for bird watchers to go and see a particular species. This may well be as most important a factor since a lot of the motivation for twitchers comes from being able to add birds to their 'life lists' and thus enhance their status. For example, there have been 10 or so record sightings of the Alpine Accentor in the last 20 years or so, but on each occasion the bird never stayed beyond a single day, and so it has not been widely 'twitchable'. Similarly, even extreme rarities may lose some of their desirability if an individual bird stays for weeks and gives enough time for most keen twitchers to see it. 
In terms of actual effort expended to see a rarity, another important issue to consider is the likelihood of seeing the species. Whilst some species might be recorded quite regularly, there may be very few opportunities to physically go and see any of the records due to the species' mobile nature. Some seabirds are recorded annually, but are invariably quick fly-pasts at coastal headlands so have never been truly 'twitchable'. Most twitchers are realistic about the prospect of seeing certain things and, even if the species is regarded as incredibly desirable, people will avoid travelling if they believe the chance of seeing it when they arrive is very low. Although seemingly paradoxical, this could simultaneously create an increased desirability but reduced motivation to travel for these particular species. Our results show that Black-browed Albatross are far more desirable within our BWS framework than the number of previous BBRC records would predict. However, there have been no truly 'twitchable' records since 1995, and none of these have been on the UK mainland. Despite this, we would not expect twitchers to travel to locations where an individual Albatross had been seen unless they had a specific reason to anticipate a high likelihood of re-sighting the bird. This would be unusual in the case of Albatross sightings.

It is possible that even if a species is rare and/or vagrant it may not attract large numbers of twitchers because the species is relatively easy to see outside of the UK. It may also be the case that vagrants from places where few people travel have a greater desirability since twitchers will never have seen one anywhere - even abroad. However, quite a few extremely rare vagrants to Britain are common in their native ranges, and even when these locations are well-travelled tourist destinations, they appear to retain very high desirability for twitchers. For example, Black-throated Blue-warblers were the highest ranked (most desirable) species across our BWS experiment, but it is a relatively common breeding bird in the South-eastern USA. One way to control for this in future research would be to ask survey respondents to check boxes if they have been bird watching in the Eastern Mediterranean, Western Mediterranean, Eastern Europe, North America and Northern Asia (generally these are the different bio-regions most vagrants originate from). By controlling for these destinations, we might be able to refine how we consider the relationship between rarity and preferences to see in the UK.

In addition to the weaknesses we identify with our measure of rarity, there is also the likelihood that taxonomic status matters. There are birds which have only recently been elevated to species-level status by the BOU Records Committee and, as such, are sometimes 
regarded with some scepticism by twitchers. The result is them not being considered as desirable as our model might otherwise expect them to be. There is also species distinctiveness. In particular, some species which are really visually impressive or distinct have a higher desirability factor. Teasing apart taxonomic distinctiveness and how visually striking a species is a complex and at times a subjective issue, but potential worthy of future research efforts. One approach to this problem might be to undertake a DCE, similar to that presented by Dissanayake and Ando (2014), so as to examine various aspects of rarity and in so doing reveal the relative importance of particular elements.

It remains unclear if twitching as an activity can be viewed as a positive or negative pursuit, either economically or environmentally. One possible economic benefit that might emerge as a result of twitching is avitourism (Steven et al., 2015). Birds bring a fascination and utility to people globally and, as a consequence, there has been a growing pursuit of 'avitourism' as a leisure activity domestically and internationally (Cordell and Herbert, 2002). In 2011 the US Fish \& Wildlife Service estimate around 17.8 million people would watch birds away from their home and the same report estimates that a staggering $\$ 41 \mathrm{bn}$ is spent annually in the US on birdwatching trips and equipment, of which $\$ 14.9 \mathrm{bn}$ is directly attributed to food, lodging and transportation. ${ }^{15}$ The implication here is that revenues from avitourism (and by extension twitching) might be used as a mechanism to aid local conservation efforts. This is a potentially interesting proposition considering that many of the twitching and vagrant bird watching sites are rather remote. Thus, twitchers could be a key source of income for these local economies, and this in turn could inject positive spillovers for local wildlife. However, the act of seeking out vagrant birds which are (by definition) alien to their surroundings can place huge stress upon otherwise fragile and/or sensitive habitats (Callaghan et al., 2018) as well as to local infrastructure. Furthermore, the fact that the birds in question are vagrant and arrive at a random destination completely unannounced means that providing suitable avitourism facilities will need to be predicated on other bird species or wildlife tourism that are not subject to such uncertainties. These issues aside, the UK is probably very well placed to offer some sort of avitourism experience - as Lees and Gilroy (2009) note, of the 580 bird species recorded in Britain at the end of 2008, 50\% are classified as vagrant. Furthermore, there are certain locations where twitchers have a higher preference for, as these sites

\footnotetext{
15 https://www.fws.gov/birds/bird-enthusiasts/bird-watching/valuing-birds.php (Access to US Fish \& Wildlife Survey Report)
} 
typically report a greater volume of rare bird sightings. This means that there have been (and continues to be) many twitchers who "stake out" certain well known locations frequently taking short trips to such destinations in anticipation and hope that something rare will appear. Classic destinations in the UK include the Isles of Scilly, Shetland and Kilnsea in East Yorkshire. For each location, this influx of twitchers and bird watchers significantly extends the conventional tourist season and most local accommodation is pre-booked by birdwatchers well in advance.

Nevertheless, there are clear costs associated with the act of twitching including (not insignificant) environmental impacts of travel, which even domestically can be extensive and involve multiple and lengthy journeys across the country. These activities have an obvious implication for carbon emissions, echoing previous concerns expressed in the literature about the negative environmental externalities from twitching (e.g., Booth et al., 2011; Kronenberg, 2014). Indeed, it may well be the case that the carbon footprint of a twitcher could easily outstrip any of the extractable economic benefits outlined above. This despite the fact that many twitchers are self-reported members of environmental organisations, and hence do signal a private interest in such conservation.

Another aspect of the arrival of vagrant birds that appears to be missing from the literature is an analysis of what happens to these birds in the longer term. As we have explained, in many cases twitchers are keen to see new vagrants as they offer a unique experience as well as a tick-mark on a life-list. But there appears to be little information or obvious expressions of concern for the vagrant species once experienced. Interestingly, although all wild birds in Britain are protected under the Wildlife and Countryside Act $(1981)^{16}$, individual vagrant birds have no specific legal protection. In the UK and Australia, individual vagrants have been occasionally captured and transported back to their native ranges, either for animal welfare reasons, or biosecurity concerns (Davis and Watson, 2018).

Another important factor that might be of far greater concern to twitchers stems from climate change and the adjusting movement of species. Jiguet and Barbet-Massin (2013) discuss how the rates of vagrancy may well be an early predictor of species movement in reaction to a

16 See for details: https://www.rspb.org.uk/birds-and-wildlife/advice/wildlife-and-the-law/wildlife-andcountryside-act/ 
gradual adaptation to climate change. If this is the case, there is a need to consider the legal protection of vagrants as noted by Davis and Watson (2018) and a discussion around longer term survival probabilities becomes more relevant. As Kolstoe et al. (2018) examine, this also opens a discussion on how climate change might affect the utility of birdwatchers as bird species move.

Finally, our analysis demonstrates that there is ample scope for using a BWS survey in environmental research. The use of DCE is now widespread in conservation research, but in many cases we argue the information required by the researchers who undertook these studies could have more easily been derived by employing a BWS survey. Whilst BWS survey design and implementation still requires serious planning and pre-testing, the potential benefits from employing this technique warrant further consideration. It is also the case, as we have done here, that employing a BWS survey online is reasonably straightforward, partly because the demands placed on respondents are much lower than with a conventional DCE.

In summary, this study has offered up some interesting results with regard to the value and expenditure of effort that the UK twitching community will go to in the pursuit of their hobby. Whilst it seems to confirm a robust and inelastic value to rarity, the economic and environmental consequences of this are ambiguous, and further research should be conducted that examines the exact implications of this activity and its relevance for the field. 


\section{References}

Apostolou, M. (2011). Why men collect things? A case study of fossilied dinosaur eggs. Journal of Economic Psychology, 32: 410-417.

Belk, R.W. (1995). Collecting as luxury consumption: Effects on individuals and households. Journal of Economic Psychology, 16: 477-490.

Booth, J.E., Gaston, K.J., Evans, K.L. and Armsworth, P.R. (2011). The value of species rarity in biodiversity recreation: A birdwatching example. Biological Conservation, 144(11): $2728-2732$.

Bristol, R., Fraser, I.M., Groombridge, J. and Veríssimo, D (2014). An Economic Analysis of Species Conservation and Translocation for Island Communities: The Seychelles Paradise Flycatchers as a Case Study, Journal of Environmental Economics and Policy, 3(3): 237-252.

Brock, M., Perino, G. and Sugden, R. (2017). The warden attitude: an investigation of the value of interaction with everyday wildlife. Environmental \& Resource Economics, 67:127155.

Czajkowski, M., Zagórska, K., Letki, N., Tryjanowski, P. and Wąs, A. (2019). Drivers of farmers' willingness to adopt extensive farming practices in a globally important bird area. Land Use Policy, 104223.

Callaghan, C.T., Slater, M., Major, R.E., Morrison, M., Martin, J.M. and Kingsford, R.T. (2018). Travelling birds generate eco-travellers: The economic potential of vagrant birdwatching. Human Dimensions of Wildlife, 23(1): 71-82.

Callaghan, C.T., Benson, I., Major, R.E., Martin, J.M., Longdon, T. and Kingsford, R.T. (2019). Birds are Valuable: The Case of Vagrants. Journal of Ecotourism, DOI: 10.1080/14724049.2019.1614010.

Casini, L., Corsi, A.M. and Goodman, S. (2009). Consumer preferences of wine in Italy applying best-worst scaling. International Journal of Wine Business Research, 21(1): 64-78 
Cordell, H.K. and Herbert, N.G. (2002). The popularity of birding is still growing. Birding, 34(1): 54-61.

Davis, R.A. and Watson, D.M. (2018). Vagrants as Vanguards of Range Shifts in a Dynamic World. Biological Conservation, 224: 238-241.

De Brauwer, M. and Burton, M. (2018). Known unknowns: Conservation and research priorities for soft sediment fauna that supports a valuable SCUBA diving industry. Ocean \& Coastal Management, 160: 30-37.

Diener E. and Biswas-Diener R. (2008). Happiness: Unlocking the Mysteries of Psychological Wealth. Blackwell.

Dissanayake, S. T. and Ando, A. W. (2014). Valuing grassland restoration: proximity to substitutes and trade-offs among conservation attributes. Land Economics, 90(2): 237-259.

Flynn, T. N., Louviere, J. J., Peters, T. J., and Coast, J. (2007). Best-worst scaling: What it can do for health care research and how to do it. Journal of Health Economics, 26, 171-189.

Gilovich, T., Kumar, A. and Jampol, L. (2015). A Wonderful Life: Experiential Consumption and the Pursuit of Happiness. Journal of Consumer Psychology, 25(1): 152-165.

Haab, T.C. and McConnell, K.E. (2002). Valuing Environmental and Natural Resources. The Econometrics of Non-Market Valuation. Edward Elgar, Cheltenham, UK \& Northampton, USA.

Holden, M.H. and McDonald-Madden, E. (2017). High prices for rare species can drive large populations extinct: the anthropogenic Allee effect revisited. Journal of Theoretical Biology, 429: $170-180$.

Jiguet, F. and Barbet-Massin, M. (2013). Climate Change and Rates of Vagrancy of Siberian Bird Species to Europe. Ibis, 155: 194-198. 
Johnson, F.R., Lancsar, E., Marshall, D., Kilambi, V., Mühlbacher, A., Regier, D.A., Bresnahan, B.W., Kanninen, B. and Bridges, J.F.P (2013). Constructing Experimental Designs for Discrete-Choice Experiments: Report of the ISPOR Conjoint Analysis Experimental Design Good Research Practices Task Force. Value in Health, 16(1): 3-13.

Koforda, K. and Tschoegl, A.E. (1998). The market value of rarity. Journal of Economic Behavior \& Organization, 34: 445-457.

Kolstoe, S. and Cameron, T.A. (2017). The Non-Market Value of Birding Sites and the Marginal Value of Additional Species: Biodiversity in a Random Utility Model of Site Choice by eBird Members. Ecological Economics, 137: 1-12.

Kolstoe, S., Cameron, T.A. and Wilsey, C. (2018). Climate, Land Cover, and Bird Populations: Differential Impacts on the Future Welfare of Birders Across the Pacific Northwest. Agricultural and Resource Economics Review, 47(2): 272-310.

Krishna, V., Darras, K., Grass, I., Mulyani, Y., Prawiradilaga, D., Tscharntke, T. and Qaim, M. (2019). Wildlife trade and consumer preference for species rarity: An examination of caged-bird markets in Sumatra. Environment and Development Economics (Available Early View).

Kronenberg, J. (2014). Environmental Impacts of the Use of Ecosystem Services: Case Study of Birdwatching. Environmental Management, 54: 617-630.

Lees, A.C. and Gilroy, J.J. (2009). Vagrancy Mechanisms in Passerines and Near-Passerines. In Slack, R. Rare Birds, Where and When: An Analysis of Status and Distribution in Britain and Ireland. Volume 1: Sandgrouse to New World Orioles. Rare Bird Books, York.

Louviere, J.J., Flynn, T.N., Marley, A.A.J. (2015). Best-worst Scaling: Theory, Methods and Applications. Cambridge University Press.

Mardon, R. and Belk, R. (2018). Materializing digital collecting: An extended view of digital materiality. Marketing Theory, 18(4): 543-570. 
Meyerhoff, J., Klefoth, T. and Arlinghaus, R. (2019). The value artificial lake ecosystems provide to recreational anglers: Implications for management of biodiversity and outdoor recreation. Journal of Environmental Management, 252: 109580.

Petrolia, D. R., Interis, M. G. and Hwang, J. (2018). Single-Choice, Repeated-Choice, and Best-Worst Scaling Elicitation Formats: Do Results Differ and by How Much?

Environmental and Resource Economics, 69(2): 365-393.

Pine II, B.J. and Gilmore, J.H. (1998). Welcome to the Experience Economy. Harvard Business Review.

Scarpa, R., Notaro, S., Louviere, J. and Raffaelli, R. (2011). Exploring Scale Effects of Best/Worst Rank Ordered Choice Data to Estimate Benefits of Tourism in Alpine Grazing Commons. American Journal of Agricultural Economics, 93(3): 813-828.

Sheard, K. (1999). A twitch in time saves nine: birdwatching, sport, and civilizing processes. Sociology of Sport Journal, 16(3): 181-205.

Solnicka, S.J. and Hemenway, D. (1998). Is more always better?: A survey on positional concerns. Journal of Economic Behavior \& Organization, 37: 373-383.

Steven, R., Morrison, C. and Castley, J.G. (2015). Birdwatching and avitourism: a global review of research into its participant markets, distribution and impacts, highlighting future research priorities to inform sustainable avitourism management. Journal of Sustainable Tourism, 23(8-9): 1257-1276.

Steven, R., Smart, J. C., Morrison, C. and Castley, J. G. (2017). Using a choice experiment and birder preferences to guide bird-conservation funding. Conservation Biology, 31(4): 818827.

Veríssimo D., Fraser, I.M., Groombridge, J., Bristol, R. and MacMillan, D.C. (2009). Birds as tourism flagship species: a case study of tropical islands. Animal Conservation, 12: 549558. 
Table 1: Best-Worst Scaling Groups, Bird Species and Rarity Measure

\begin{tabular}{|c|c|c|}
\hline Group/Profiles & Bird Species & $\begin{array}{l}\text { Measure Rarity - BBRC Score \& } \\
\text { Estimate }\end{array}$ \\
\hline \multirow[t]{5}{*}{ Rare 1} & Siberian Accentor & 13 \\
\hline & Black-billed Cuckoo & 14 \\
\hline & Pied Wheatear & 78 \\
\hline & Squacco Heron & 103 \\
\hline & Gull-billed Tern & 313 \\
\hline \multirow[t]{5}{*}{ Rare 2} & Black-faced Bunting & 6 \\
\hline & Calandra Lark & 19 \\
\hline & Collared Flycatcher & 46 \\
\hline & Pine Bunting & 56 \\
\hline & Thrush Nightingale & 213 \\
\hline \multirow[t]{5}{*}{ Rare 3} & Western Sandpiper & 9 \\
\hline & Black-browed Albatross & 35 \\
\hline & Gyr Falcon & 182 \\
\hline & Red-flanked Bluetail & 180 \\
\hline & Aquatic Warbler & 1357 \\
\hline \multirow[t]{5}{*}{ Extremely Rare } & $\begin{array}{l}\text { Double-crested } \\
\text { Cormorant }\end{array}$ & 1 \\
\hline & Rufous Bush Chat & 5 \\
\hline & Ruppell's Warbler & 5 \\
\hline & Eastern Bonelli's Warbler & 15 \\
\hline & Sociable Plover & 40 \\
\hline \multirow[t]{5}{*}{ Future } & Azure Tit & Russia and Siberia \\
\hline & Bonelli's Eagle & Southern Europe/ Mediterranean \\
\hline & $\begin{array}{l}\text { Black-throated Blue } \\
\text { Warbler }\end{array}$ & $\begin{array}{l}\text { Rarely found in Western Europe - } \\
\text { (from North America) }\end{array}$ \\
\hline & Intermediate Egret & Africa \\
\hline & Slender-billed Curlew & Potentially extinct - last sighted 1995 \\
\hline \multirow[t]{5}{*}{ Scarce } & Grey Phalarope & $\begin{array}{l}\text { Approximately } 200 \text { sightings per year } \\
\text { depending on weather systems }\end{array}$ \\
\hline & Dotterel & $\begin{array}{l}\text { Summer visitor, with inaccessible } \\
\text { breeding range in Scottish highlands } \\
\text { Red List* }\end{array}$ \\
\hline & Red-backed Shrike & Scare passage migrant - Red List* \\
\hline & Common Rosefinch & $>695$ \\
\hline & Velvet Scoter & $\begin{array}{l}\text { Coastal winter visitor, rare inland - Red } \\
\text { List* }\end{array}$ \\
\hline
\end{tabular}

Notes: * Red is the highest conservation priority, with species needing urgent action. The list criteria include: Species is globally threatened; Historical population decline in UK during 1800-1995; Severe (at least 50\%) decline in UK breeding population over last 25 years, or longer-term period (the entire period used for assessments since the first BoCC review, starting in 1969); Severe (at least 50\%) contraction of UK breeding range over last 25 years, or the longer-term period. https:/www.rspb.org.uk/birds-and-wildlife/wildlifeguides/uk-conservation-status-explained/\#1HgOFdXVzdj50feq.99 
Table 2: Regression Variables

\begin{tabular}{|l|l|l|}
\hline Variable & Description & Units \\
\hline LINVRAR & Log inverse of the rarity score for each species & Count \\
\hline LCOST & Log total cost of the trip made & Monetary \\
\hline TBEFORE & Travel before sighting has been officially confirmed & Yes/No \\
\hline BEYUK & Travel beyond the UK to see rare birds & Yes/No \\
\hline TT & Total bird watching trips made in 2015, 2016 and 2017 & Count \\
\hline RBNS & Information source - Rare Bird Network Service & Yes/No \\
\hline FB & Information source - Facebook/Twitter & Yes/No \\
\hline Whats & Information source - Whatsapp Group & Yes/No \\
\hline TEXT & Information source - Text & Yes/No \\
\hline RBA & Information source - Rare Bird Alert web subscription & Yes/No \\
\hline RBAP & Information source - Rare Bird Alert Pager & Yes/No \\
\hline BWS & Information source - Birdguides web subscription & Yes/No \\
\hline RSPB & Member of Royal Society Preservation of Birds & Yes/No \\
\hline BLI & Member of BirdLife International & Yes/No \\
\hline BOU & Member of British Ornithologists' Union & Yes/No \\
\hline NT & Member of National Trust & Yes/No \\
\hline OTHER & Member of Other Conservation Organisations & Yes/No \\
\hline AGE & Years & Years \\
\hline EDU & Highest level of education & Categorica \\
\hline GENDER & Male or Female & 1 \\
\hline LNINC & Log Annual Household Income & Binary \\
\hline & & Monetary \\
\hline
\end{tabular}


Table 3: Regression Results for One-Trip Data Set

\begin{tabular}{|c|c|c|c|c|c|c|c|c|c|c|c|c|}
\hline & \multicolumn{6}{|c|}{ One Trip Data Set } & \multicolumn{6}{|c|}{ Multi-Trip Data Set } \\
\hline & \multicolumn{3}{|c|}{ Base Model $(n=224)$} & \multicolumn{3}{|c|}{ Rarity Index $(n=212)$} & \multicolumn{3}{|c|}{ Base Model $(n=1042)$} & \multicolumn{3}{|c|}{ Rarity Index $(n=843)$} \\
\hline & Coeff & SE & $\mathbf{P}$ & Coeff & SE & $\mathbf{P}$ & Coeff & SE & $\mathbf{P}$ & Coeff & SE & $\mathbf{P}$ \\
\hline Constant & $-6.37 * * *$ & 1.06 & 0.00 & $-4.97 * * *$ & 1.04 & 0.00 & $-5.43 * * *$ & 0.47 & 0.00 & $-4.26 * * *$ & 0.58 & 0.00 \\
\hline LCOST & $0.47 * * *$ & 0.12 & 0.00 & $0.42 * * *$ & 0.11 & 0.00 & $0.53 * * *$ & 0.06 & 0.00 & $0.29 * * *$ & 0.06 & 0.00 \\
\hline TBEFORE & 0.47 & 0.29 & 0.11 & $0.57 * *$ & 0.26 & 0.03 & 0.19 & 0.15 & 0.23 & 0.18 & 0.14 & 0.21 \\
\hline BEYUK & & & & & & & $-0.01 * * *$ & 0.00 & 0.00 & -0.11 & 0.15 & 0.44 \\
\hline TT & & & & & & & $-0.01 * * *$ & 0.00 & 0.00 & $-0.01 * * *$ & 0.00 & 0.00 \\
\hline RBNS & 0.26 & 0.31 & 0.40 & 0.16 & 0.28 & 0.56 & 0.16 & 0.16 & 0.31 & 0.16 & 0.15 & 0.30 \\
\hline FB & $-0.62 *$ & 0.34 & 0.08 & -0.43 & 0.31 & 0.16 & $-0.78 * * *$ & 0.19 & 0.00 & $-0.64 * * *$ & 0.17 & 0.00 \\
\hline Whats & -0.06 & 0.34 & 0.86 & 0.15 & 0.31 & 0.62 & 0.25 & 0.18 & 0.17 & 0.06 & 0.17 & 0.71 \\
\hline TEXT & $0.60 *$ & 0.31 & 0.05 & 0.35 & 0.28 & 0.22 & $0.48^{* * *}$ & 0.16 & 0.00 & $0.44 * * *$ & 0.15 & 0.00 \\
\hline RBA & 0.03 & 0.32 & 0.93 & -0.25 & 0.28 & 0.39 & $0.60 * * *$ & 0.17 & 0.00 & $0.36 * *$ & 0.16 & 0.03 \\
\hline RBAP & $0.88^{* *}$ & 0.38 & 0.02 & $0.83 * *$ & 0.33 & 0.01 & $0.81 * * *$ & 0.20 & 0.00 & $0.42 * *$ & 0.19 & 0.03 \\
\hline BWS & $0.59 *$ & 0.33 & 0.08 & 0.28 & 0.29 & 0.35 & $0.41 * *$ & 0.17 & 0.02 & $0.47 * * *$ & 0.17 & 0.00 \\
\hline RSPB & -0.54 & 0.35 & 0.13 & -0.48 & 0.32 & 0.14 & -0.13 & 0.19 & 0.51 & -0.16 & 0.18 & 0.39 \\
\hline BLI & 0.19 & 0.47 & 0.69 & 0.64 & 0.43 & 0.14 & -0.30 & 0.25 & 0.24 & -0.16 & 0.24 & 0.51 \\
\hline BOU & $1.41 * *$ & 0.55 & 0.01 & $1.03 * *$ & 0.48 & 0.03 & $-0.52 *$ & 0.28 & 0.07 & 0.12 & 0.29 & 0.68 \\
\hline NT & -0.25 & 0.38 & 0.51 & -0.36 & 0.33 & 0.29 & $-0.55 * * *$ & 0.20 & 0.01 & -0.27 & 0.19 & 0.16 \\
\hline OTHER & $-0.54 *$ & 0.30 & 0.07 & $-0.54 * *$ & 0.27 & 0.05 & -0.26 & 0.16 & 0.11 & -0.19 & 0.15 & 0.21 \\
\hline AGE & 0.01 & 0.01 & 0.65 & 0.01 & 0.01 & 0.57 & 0.01 & 0.01 & 0.39 & 0.01 & 0.01 & 0.11 \\
\hline EDU & -0.14 & 0.13 & 0.28 & -0.15 & 0.11 & 0.20 & -0.003 & 0.01 & 0.65 & $-0.20 * * *$ & 0.06 & 0.00 \\
\hline GENDER & $1.17 * *$ & 0.58 & 0.05 & 0.30 & 0.59 & 0.62 & $0.002 * *$ & 0.00 & 0.01 & -0.38 & 0.34 & 0.26 \\
\hline LNINC & 0.05 & 0.11 & 0.61 & 0.04 & 0.10 & 0.68 & -0.000 & 0.00 & 0.65 & $0.25 * * *$ & 0.11 & 0.03 \\
\hline $\mathbf{R}^{2}$ & \multicolumn{3}{|c|}{0.26} & \multicolumn{3}{|c|}{0.24} & \multicolumn{3}{|c|}{0.17} & \multicolumn{3}{|c|}{0.12} \\
\hline
\end{tabular}

Note: ${ }^{* * *}, * *, *$ implies significance at $1 \%, 5 \%$ and $10 \%$ level. Coeff $=$ Coefficient. $\mathrm{SE}=$ Standard Error. $\mathrm{P}=\mathrm{P}$ Value 
Table 4: CL Estimates, Relative Species Rank and and BBRC List Score

\begin{tabular}{|c|c|c|c|c|c|}
\hline Species (Group) & $\begin{array}{l}\text { Estimates } \\
\text { CL }\end{array}$ & $\begin{array}{l}\text { Rank } \\
\text { CL }\end{array}$ & $\begin{array}{l}\text { BWS } \\
\text { Score }\end{array}$ & $\begin{array}{l}\text { Rank } \\
\text { BWS }\end{array}$ & $\begin{array}{l}\text { BBRC } \\
\text { Score }\end{array}$ \\
\hline Aquatic Warbler (R3) & $0.739 * *$ & 15 & 10 & 14 & 1357 \\
\hline Azure Tit $(\mathrm{P})$ & $2.984 * * *$ & 2 & 75 & 2 & 0 \\
\hline Black-billed Cuckoo (R1) & $1.747 * * *$ & 4 & 46 & 5 & 14 \\
\hline Black-browed Albatross (R3) & $2.520 * * *$ & 18 & -3 & 17 & 35 \\
\hline Black-faced Bunting (R2) & 0.385 & 9 & 23 & 8 & 6 \\
\hline $\begin{array}{l}\text { Black-throated Blue Warbler } \\
\text { (P) }\end{array}$ & $3.262 * * *$ & 1 & 81 & 1 & 0 \\
\hline Bonelli's Eagle $(\mathrm{P})$ & $1.985 * * *$ & 7 & 40 & 6 & 0 \\
\hline Calandra Lark (R2) & $0.864 * * *$ & 14 & 12 & 11 & 19 \\
\hline Collared Flycatcher (R2) & $1.073 * * *$ & 13 & 8 & 15 & 46 \\
\hline Common Rosefinch (S) & $-1.749 * * *$ & 29 & -97 & 28 & 695 \\
\hline Dotterel (S) & $-1.084 * * *$ & 26 & -47 & 26 & 9000 \\
\hline Double-crested Cormorant (E) & $-1.007 * * *$ & 25 & -29 & 25 & 1 \\
\hline Eastern Bonelli's Warbler (E) & -0.107 & 21 & -10 & 22 & 15 \\
\hline Grey Phalarope (S) & $-1.567 * * *$ & 28 & -103 & 29 & 8000 \\
\hline Gull-billed Tern (R1) & -0.179 & 22 & -10 & 21 & 313 \\
\hline Gyr Falcon (R3) & $2.513 * * *$ & 5 & 49 & 4 & 182 \\
\hline Intermediate Egret $(\mathrm{P})$ & $-0.833 * * *$ & 23 & -20 & 24 & 0 \\
\hline Pied Wheatear (R1) & 0.548 & 16 & -1 & 16 & 78 \\
\hline Pine Bunting (R2) & 0.499 & 17 & -3 & 18 & 56 \\
\hline Red-backed Shrike (S) & $-1.125 * * *$ & 12 & 11 & 13 & 2000 \\
\hline Red-flanked Bluetail (R3) & $1.172 * * *$ & 27 & -52 & 27 & 180 \\
\hline Rufous Bush Chat (E) & $2.205 * * *$ & 6 & 34 & 7 & 5 \\
\hline Ruppell's Warbler (E) & $1.520 * * *$ & 10 & 17 & 10 & 5 \\
\hline Siberian Accentor (R1) & $1.824 * * *$ & 23 & -15 & 23 & 13 \\
\hline Slender-billed Curlew (P) & $2.963 * * *$ & 8 & 22 & 9 & 0 \\
\hline Sociable Plover $(\mathrm{E})$ & $1.296 * * *$ & 3 & 74 & 3 & 40 \\
\hline Squacco Heron (R1) & -0.394 & 11 & 12 & 12 & 103 \\
\hline Thrush Nightingale (R2) & -0.072 & 20 & -8 & 20 & 213 \\
\hline Velvet Scoter $(\mathrm{S})$ & $-3.066 * * *$ & 30 & -110 & 30 & 5000 \\
\hline Western Sandpiper (R3) & $\mathrm{n} / \mathrm{a}$ & 19 & -6 & 19 & 9 \\
\hline
\end{tabular}

Statistical Significance: *** 1\%;**5\%; *10\%

Note: BWS $=$ Best-Worst Scaling; $\mathrm{CL}=$ Conditional Logit 


\section{Figure 1: Example BWS Choice Task}

We are going to ask you to make 5 separate choices. In each case you will be presented with a group of 6 birds. You will be asked to select the bird you would most enjoy seeing as well as the bird you would least enjoy seeing. You make your choices by ticking the boxes as shown in the example set below:

\begin{tabular}{|l|c|l|}
\hline $\begin{array}{l}\text { Most Enjoy } \\
\text { Seeing }\end{array}$ & $\begin{array}{l}\text { Least Enjoy } \\
\text { Seeing }\end{array}$ \\
\hline & Siberian Accentor & \\
\hline & Black-faced Bunting & \\
\hline & Western Sandpiper & \\
\hline & Rufous Bush Chat & \\
\hline & Azure Tit & \\
\hline & Grey Phalarope & \\
\hline
\end{tabular}


Appendix Table A1: Descriptive Statistics: Travel Cost and Best-Worts Scaling Samples

\begin{tabular}{|c|c|c|c|}
\hline Variable & Label & $\mathrm{N}=\mathbf{2 2 4}$ & $\mathrm{N}=125$ \\
\hline Gender (Male \%) & $0=$ Female $; 1=$ Male & 93.0 & 92.0 \\
\hline $\begin{array}{l}\text { Marital Status (Married } \\
\% \text { ) }\end{array}$ & $0=$ Not Married; $1=$ Married & 69.0 & 65.6 \\
\hline $\begin{array}{l}\text { Work Status (Full Time } \\
\% \text { ) }\end{array}$ & $\begin{array}{l}0=\text { Not Full Time; } 1=\text { Full } \\
\text { Time }\end{array}$ & 61.0 & 56.9 \\
\hline Age (Years) & Years (Average) & 49 & 48 \\
\hline Education (\%) & $\begin{array}{l}\text { High school (GCSEs, A } \\
\text { levels) } \\
\text { College (BTEC/HND, etc) } \\
\text { Undergraduate degree } \\
\text { Postgraduate degree }\end{array}$ & $\begin{array}{l}24.1 \\
17.4 \\
28.6 \\
29.0\end{array}$ & $\begin{array}{l}20.0 \\
12.0 \\
29.6 \\
38.4\end{array}$ \\
\hline $\begin{array}{l}\text { Annual Household } \\
\text { income before tax }(\%)\end{array}$ & $\begin{array}{l}\text { Less than } £ 10,000 \\
£ 10,000-£ 24,999 \\
£ 25,000-£ 39,999 \\
£ 40,000-£ 59,999 \\
£ 60,000-£ 79,999 \\
£ 80,000 \text { or more }\end{array}$ & $\begin{array}{l}3.1 \\
15.2 \\
21.0 \\
25.9 \\
10.7 \\
15.6\end{array}$ & $\begin{array}{l}3.5 \\
14.2 \\
26.5 \\
26.5 \\
8.8 \\
20.3\end{array}$ \\
\hline Life-list (\%) & $0=$ No Life-list; $1=$ Life-list & 90.0 & 91.0 \\
\hline Travel Before $(\%)$ & $\begin{array}{l}0=\text { No Travel; } 1=\text { Yes } \\
\text { Travel }\end{array}$ & 45 & 43.8 \\
\hline $\begin{array}{l}\text { Member of wildlife or } \\
\text { conservation } \\
\text { organisation }(\%)\end{array}$ & $\begin{array}{l}\text { Royal Society for the } \\
\text { Protection of Birds } \\
\text { Bird Life International } \\
\text { British Ornithologists' } \\
\text { Union } \\
\text { National Trust } \\
\text { Other }\end{array}$ & $\begin{array}{l}79.9 \\
9.4 \\
7.1 \\
17.0 \\
65.6\end{array}$ & $\begin{array}{l}80.0 \\
8.9 \\
7.0 \\
17.1 \\
65.0\end{array}$ \\
\hline $\begin{array}{l}\text { Information Service } \\
\text { Used to Indicate Rare } \\
\text { Bird Sightings (\%) }\end{array}$ & $\begin{array}{l}\text { Rare Bird Network } \\
\text { Service } \\
\text { Facebook/Twitter } \\
\text { Whatsapp Group } \\
\text { Text } \\
\text { Rare Bird Alert } \\
\text { Rare Bird Alert Pager } \\
\text { Birdguides Web } \\
\text { Subscription } \\
\text { Other }\end{array}$ & $\begin{array}{l}53.6 \\
73.7 \\
25.4 \\
37.5 \\
31.7 \\
22.8 \\
42.4 \\
27.2\end{array}$ & $\begin{array}{l}46.0 \\
71.0 \\
27.2 \\
36.1 \\
30.4 \\
23.2 \\
41.8 \\
25.1\end{array}$ \\
\hline
\end{tabular}




\section{Appendix Table A2: Lists of Birds for Best Twitch in 2017}

\begin{tabular}{|l|l|l|l|l|}
\hline Alpine Accentor & Dusky Thrush & Lesser Grey Shrike & Radde's Warbler & Spotted Sandpiper \\
\hline $\begin{array}{l}\text { American Horned } \\
\text { Lark }\end{array}$ & Dusky Warbler & Lesser Yellowlegs & Red-throated Pipit & Steppe Grey Shrike \\
\hline American Redstart & $\begin{array}{l}\text { Eastern Orphean } \\
\text { Warbler }\end{array}$ & Little bunting & Red-winged Blackbird & Stilt Sandpiper \\
\hline American Wigeon & Elegant Tern & Little Egret & Red-breasted Flycatcher & Surf scoter \\
\hline Amur Falcon & Eurasian Scops Owl & $\begin{array}{l}\text { Long-Billed } \\
\text { Dowitcher }\end{array}$ & Red-footed Falcon & ThaySr`s Gull \\
\hline Arctic Redpoll & European Bee-eater & Marsh Sandpiper & Ring-necked Duck & Thrush Nightingale \\
\hline $\begin{array}{l}\text { Black-billed } \\
\text { Cuckoo }\end{array}$ & Fea's Petrel & Pacific Diver & Rock Thrush & $\begin{array}{l}\text { Two-barred Greenish } \\
\text { Warbler }\end{array}$ \\
\hline $\begin{array}{l}\text { Black-browed } \\
\text { Albartross }\end{array}$ & Glaucous Gull & $\begin{array}{l}\text { Pallas's Grasshopper } \\
\text { Warbler }\end{array}$ & Rose-coloured Starling & White-winged Scoter \\
\hline $\begin{array}{l}\text { Black Throated } \\
\text { Thrush }\end{array}$ & Great Shearwater & Pallid Harrier & Ross' Gull & Wilson's Phalarope \\
\hline Blue Rock Thrush & Green-winged Teal & Pallid Swift & Savi's Warbler & Wilsons Storm Petrel \\
\hline Bluethroat & Hawfinch & Parrott Crossbill & $\begin{array}{l}\text { Semi-palmated } \\
\text { Sandpiper }\end{array}$ & Woodchat Shrike \\
\hline $\begin{array}{l}\text { Buff Breasted } \\
\text { Sandpiper }\end{array}$ & Hen Harrier & Penduline Tit & Shore Lark & Yellow Warbler \\
\hline Caspian Tern & Hooded Merganser & Pied-billed Grebe & Siberian Accentor & Yellow-billed Cuckoo \\
\hline Cedar Waxwing & Isabelline Wheatear & Pine Bunting & Siberian Thrush & \\
\hline Cliff Swallow & Least Sandpiper & Purple Heron & Snowy Owl & \\
\hline
\end{tabular}

The locations visited include: Staines Reservoir, Surrey, Barra, Outer Hebrides, Polgigga, Cornwall, Pagham Harbour, Sussex; Isles of Scilly; Spurn Point, East Yorkshire; Flamborough Head; North Ronaldsay, Orkney; Pwll-du, Gwent, South Wales; Portland, Dorset; Fair Isle, Orkney Islands; Titchwell RSPB, Norfolk. 


\section{Appendix Table 3A: Extra Model Specifications}

\begin{tabular}{|c|c|c|c|c|c|c|c|c|c|c|c|c|}
\hline & \multicolumn{6}{|c|}{ One Trip Data Set } & \multicolumn{6}{|c|}{ Multi-Trip Data Set } \\
\hline & \multicolumn{3}{|c|}{$\begin{array}{c}\text { Random Coefficient } \\
(n=224)\end{array}$} & \multicolumn{3}{|c|}{ Twitching Only $(n=183)$} & \multicolumn{3}{|c|}{$\begin{array}{l}\text { Panel Random Effects } \\
(n=1042)\end{array}$} & \multicolumn{3}{|c|}{$\begin{array}{c}\text { Random Coefficients } \\
(\mathrm{n}=1042)\end{array}$} \\
\hline & Coeff & SE & $\mathbf{P}$ & Coeff & $\mathbf{S E}$ & $\mathbf{P}$ & Coeff & SE & $\mathbf{P}$ & Coeff & SE & $\mathbf{P}$ \\
\hline Constant & $-6.44 * * *$ & 1.00 & 0.00 & $-5.48 * * *$ & 1.13 & 0.00 & $-5.89 * * *$ & 0.70 & 0.00 & $-5.78 * * *$ & 0.59 & 0.00 \\
\hline LCOST & $0.47 * * *$ & 0.11 & 0.00 & $0.51 * * *$ & 0.13 & 0.00 & $0.43 * * *$ & 0.07 & 0.00 & $0.51 * * *$ & 0.06 & 0.00 \\
\hline TBEFORE & $0.52 *$ & 0.27 & 0.05 & 0.18 & 0.31 & 0.56 & 0.06 & 0.18 & 0.73 & 0.20 & 0.16 & 0.22 \\
\hline BEYUK & & & & & & & -0.28 & 0.19 & 0.14 & $-0.31 *$ & 0.16 & 0.06 \\
\hline TT & & & & & & & $-0.01 * * *$ & 0.00 & 0.00 & $-0.01 * * *$ & 0.00 & 0.00 \\
\hline RBNS & 0.26 & 0.30 & 0.38 & -0.07 & 0.32 & 0.83 & 0.22 & 0.19 & 0.27 & 0.17 & 0.17 & 0.30 \\
\hline FB & $-0.58 *$ & 0.34 & 0.09 & $-0.71 *$ & 0.37 & 0.06 & $-0.66^{* * *}$ & 0.24 & 0.01 & $-0.73 * * *$ & 0.19 & 0.00 \\
\hline Whats & -0.05 & 0.31 & 0.87 & 0.08 & 0.35 & 0.81 & $0.56^{* *}$ & 0.23 & 0.01 & 0.25 & 0.19 & 0.19 \\
\hline TEXT & $0.63 * *$ & 0.31 & 0.04 & $0.55^{*}$ & 0.34 & 0.10 & $0.53 * * *$ & 0.20 & 0.01 & $0.54 * * *$ & 0.17 & 0.00 \\
\hline RBA & 0.01 & 0.30 & 0.97 & -0.07 & 0.33 & 0.84 & $0.49 * *$ & 0.21 & 0.02 & $0.50 * * *$ & 0.18 & 0.01 \\
\hline RBAP & $0.83^{* *}$ & 0.36 & 0.02 & $0.75^{*}$ & 0.38 & 0.05 & $0.98 * * *$ & 0.26 & 0.00 & $0.74 * * *$ & 0.23 & 0.00 \\
\hline BWS & $0.55^{*}$ & 0.31 & 0.07 & 0.25 & 0.36 & 0.49 & $0.55^{* * *}$ & 0.21 & 0.01 & $0.47 * *$ & 0.18 & 0.01 \\
\hline RSPB & -0.56 & 0.35 & 0.11 & $-0.78 * *$ & 0.37 & 0.04 & -0.05 & 0.24 & 0.84 & -0.06 & 0.20 & 0.76 \\
\hline BLI & 0.19 & 0.38 & 0.62 & 0.62 & 0.54 & 0.25 & -0.44 & 0.30 & 0.14 & -0.26 & 0.25 & 0.31 \\
\hline BOU & $1.46^{* *}$ & 0.58 & 0.01 & $1.57 * * *$ & 0.59 & 0.01 & $-0.61 *$ & 0.35 & 0.08 & $-0.59 * *$ & 0.27 & 0.03 \\
\hline NT & -0.28 & 0.35 & 0.43 & -0.34 & 0.38 & 0.37 & $-0.52 * *$ & 0.25 & 0.04 & $-0.53 * * *$ & 0.20 & 0.01 \\
\hline OTHER & $-0.55^{*}$ & 0.29 & 0.06 & $-0.93 * * *$ & 0.32 & 0.00 & -0.26 & 0.19 & 0.19 & -0.17 & 0.17 & 0.32 \\
\hline AGE & 0.01 & 0.01 & 0.53 & 0.00 & 0.01 & 0.94 & 0.01 & 0.01 & 0.32 & 0.01 & 0.01 & 0.61 \\
\hline EDU & -0.13 & 0.12 & 0.27 & -0.12 & 0.14 & 0.38 & $-0.14 *$ & 0.08 & 0.08 & $-0.13^{*}$ & 0.07 & 0.06 \\
\hline GENDER & $1.14 * *$ & 0.49 & 0.02 & $1.49 * *$ & 0.62 & 0.02 & 0.27 & 0.38 & 0.49 & 0.41 & 0.30 & 0.16 \\
\hline$\overline{\text { LNINC }}$ & 0.05 & 0.10 & 0.66 & 0.03 & 0.12 & 0.83 & $0.32 * *$ & 0.14 & 0.02 & $0.22 *$ & 0.12 & 0.05 \\
\hline $\mathbf{R}^{2}$ & & & & & $2(0.24$ & & & & & & & \\
\hline $\mathbf{L L}$ & & \multicolumn{2}{|c|}{-464.46} & & & & \multicolumn{3}{|c|}{-1924.23} & \multicolumn{3}{|c|}{-2135.82} \\
\hline \multicolumn{2}{|c|}{ Scale Parameter } & & & & & & & & & & & \\
\hline LCOST & $0.07 * *$ & 0.03 & 0.01 & & & & & & & 0.00 & 0.02 & 0.99 \\
\hline LNINC & $0.19 * * *$ & 0.04 & 0.00 & & & & & & & $0.09 * * *$ & 0.02 & 0.00 \\
\hline
\end{tabular}

Note: $* * *, * *, *$ implies significance at $1 \%, 5 \%$ and $10 \%$ level. Coeff $=$ Coefficient. SE $=$

Standard Error. P $=$ P Value. LL $=$ Log-Likelihood 
Appendix A4: Copy of Survey Instrument.

A pdf version of the survey instrument is provided as an additional document. 